\title{
Presentation of Branchial Cleft Anomalies: Case Reports and Review of Literature
}

\author{
Apar Pokharel, ${ }^{1}$ TS Rao, Bikash Pandey, ${ }^{1}$ Chhanya Bhandary, ${ }^{1}$ Prashant Bhatt, ${ }^{1}$ Suvechhya Jaiswal ${ }^{2}$ \\ ${ }^{1}$ Department of Otorhinolaryngology and Head and Neck Surgery, ${ }^{2}$ Department of Pathology, College of Medical \\ sciences, Chitwan, Nepal.
}

\begin{abstract}
Type 2 branchial cleft anomalies are the most common cause of lateral neck swelling. We report two cases of type 2 branchial cleft anomalies. The first case is branchial cleft cyst and the second one is branchial fistula. Both cases were managed surgically. The post operative outcomes were uneventful. Second branchial cleft anomalies are the most common branchial anomalies. Branchial cysts are more common than sinuses and branchial fistulae are extremely rare. There is no gender predilection. The location, clinical symptoms and imaging findings aid in the diagnosis of this condition. Surgical excision is the mainstay of treatment.
\end{abstract}

Keywords: branchial cleft; branchial cyst; branchial fistula.

\section{INTRODUCTION}

The term branchial cyst was first coined by Ascherson in $1832 .{ }^{1}$ The branchial arches are the precursors of the face, neck and pharynx development. Branchial arch anomalies are the second most common congenital lesions of the head and neck in children after thyroglossal duct anomalies. ${ }^{2}$ The branchial arches develop between the fourth and seventh week of intrauterine life. Six pairs of branchial arches are present on either side of the pharyngeal foregut. The fifth arch is usually only rudimentary, or absent.Therefore only five arches formulate adult structures., ${ }^{2,3}$ Branchial cleft cysts and sinuses comprises $20 \%$ of cervical masses in children. ${ }^{3}$ The branchial cysts are classified into four types. The second branchial cleft cyst represents $95 \%$ of all branchial anomalies. ${ }^{4-6}$ These cysts or sinuses are present along the anterior border of the upper third of the sternocleidomastoid muscle. The second branchial sinus can extend from the skin of the lateral neck, between the internal and external carotid arteries, upto the palatine tonsil. $^{7}$

We report two cases of second branchial cleft anomalies, one presenting as branchial sinus and the other presenting as branchial cyst.

\section{CASE REPORT}

\section{Case 1}

A fifty year old male patient came with a chief complaint of swelling in the right lower jaw since 6 months. On examination, a swelling was seen below the angle of the mandible measuring $6 \times 4 \mathrm{~cm}$ (Figure 1).

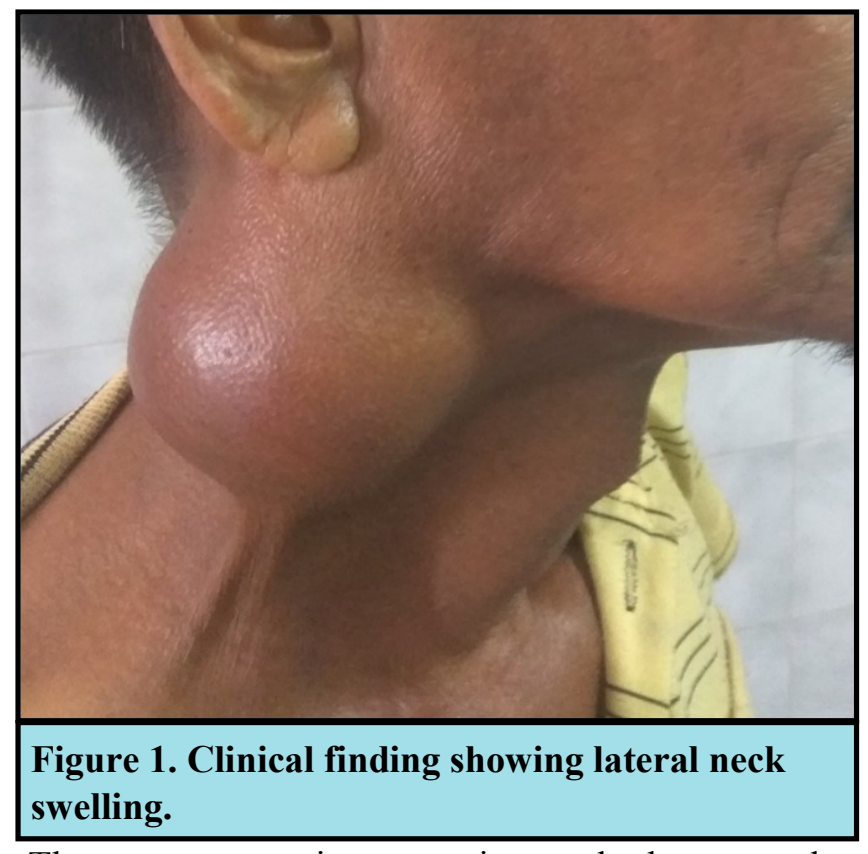

The mass was just anterior and deep to the sternocleidomastoid muscle. On palpation the swelling was soft, fluctuant and non-tender. FNAC was performed which showed findings consistent of branchial cyst. The computed tomographic scan showed $6 \times 4 \times 6 \mathrm{~cm}$ cystic mass in the right posterior triangle of the neck extending into the carotid space and encasing the internal jugular vein and carotid artery (Figure 2).

Correspondence: Dr. Apar Pokharel, Department of Otorhinolaryngology and Head and Neck Surgery, College of Medical Sciences, Chitwan, Nepal. Email: aparpokharel@hotmail.com. Phone: +977-9841558234. DOI: $10.3126 /$ jcmsn.v14i3.21005. Article received: 2018-09-05. Article accepted: 2018-09-16. 


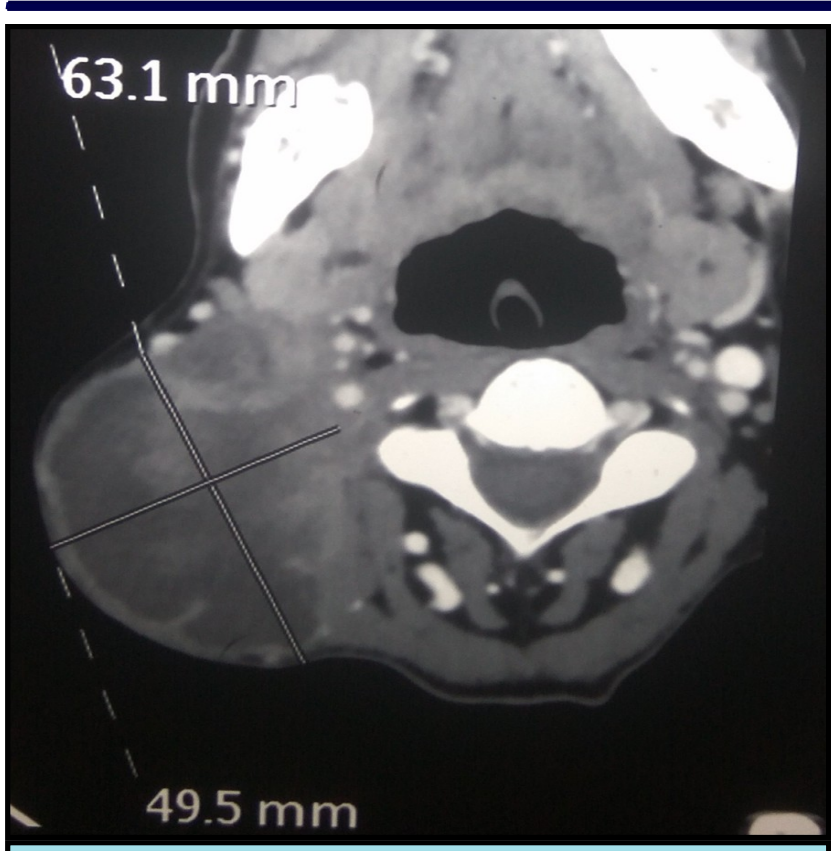

Figure 2. CT scan of the branchial cyst.

The patient was operated and a cystic mass containing yellowish brown fluid was excised. The post operative period was uneventful (Figure 3).

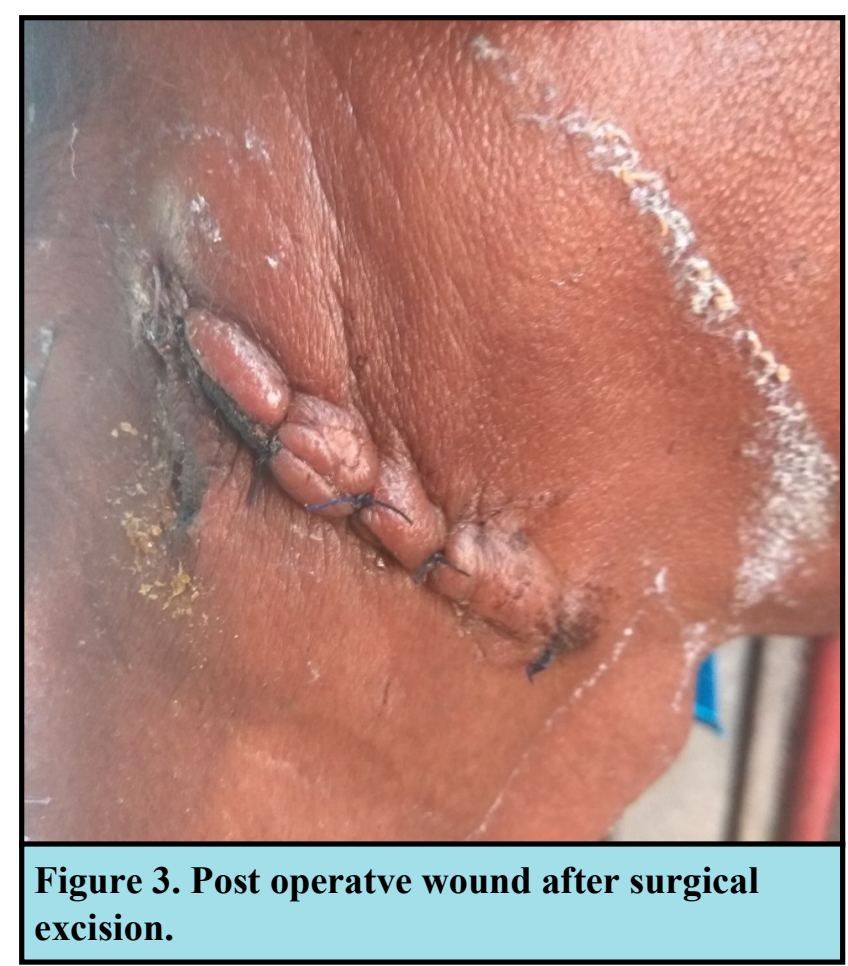

On histopathology, the cyst wall consists of infiltration by chronic inflammatory cells was visualized with features of squamous cell carcinoma (Figure 4).

\section{Case 2}

A 16 year old female patient came with complaints of on and off discharge from the right side of neck

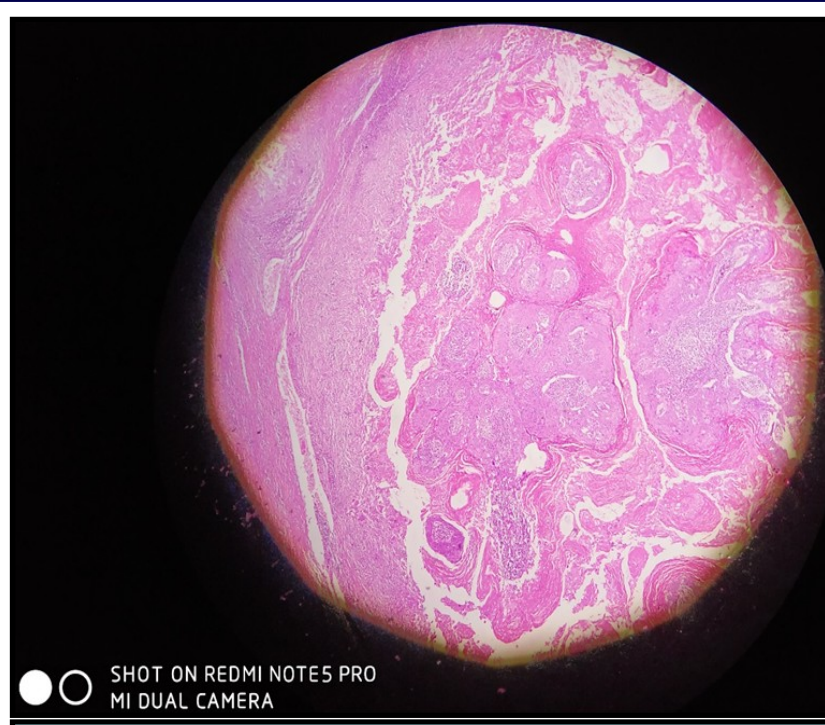

Figure 4. Histopathology slide of branchial cyst.

since birth. There was no past historyof trauma nor any operative intervention. On examination, a pinhead opening along the anterior border of sternocleidomastoid muscle was seen on the lower third of neck. A sonogram study using iodinated contrast media showed a tract coursing cranially up to the right tonsillar fossa. There was no spillage of contrast at the cranial end (Figure 5).

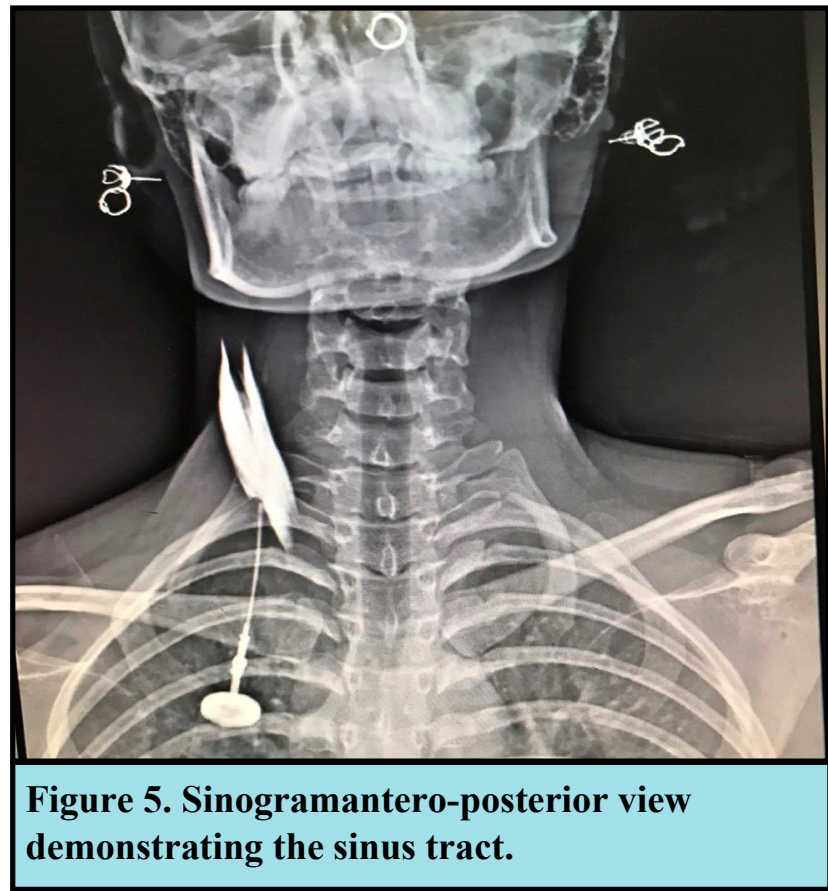

A diagnosis of second arch branchial fistula was made. Surgical excision of the tract via step ladder approach was done (Figure 6). A sinus tract of $3 \mathrm{x}$ $1 \mathrm{~cm}$ was excised. The postoperative period was uneventful (Figure 7). On histopathological examination, a sinus tract lined by chronic inflammatory cells was seen (Figure 8). 
Pokharel et al. Presentation of Branchial Cleft Anomalies: Case Reports and Review of..
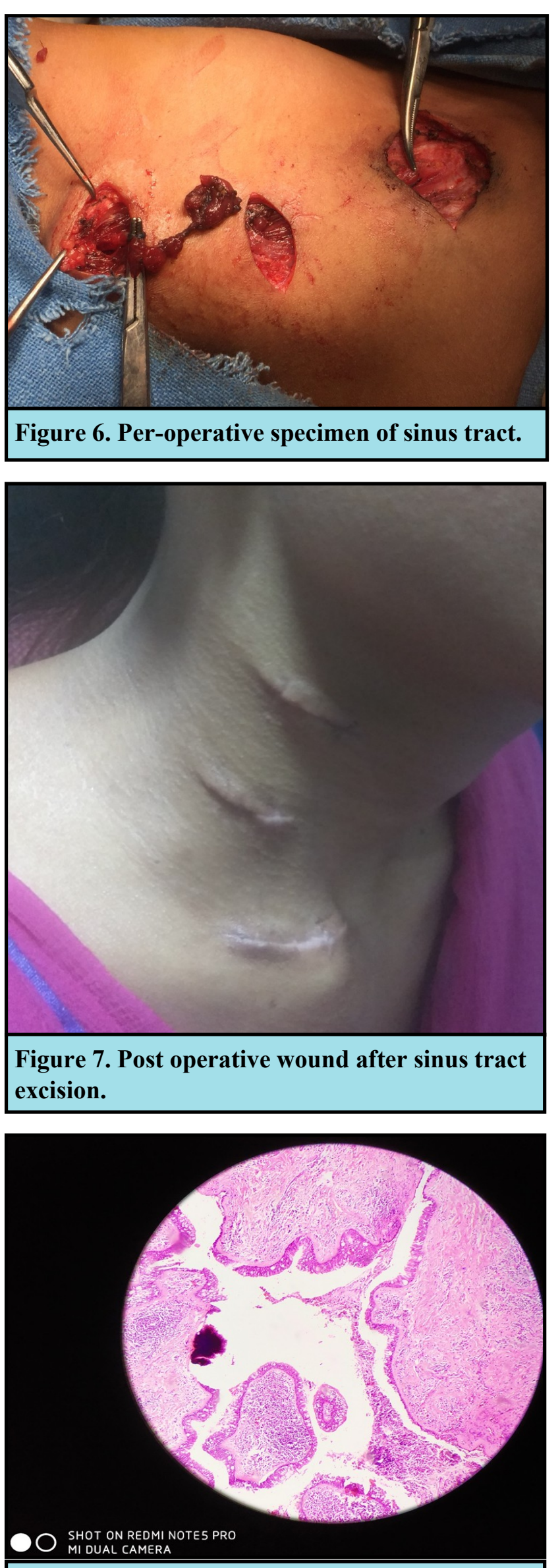

Figure 8. Histopathology of branchial sinus.

\section{DISCUSSION}

Branchial apparatus anomalies can result in various abnormal conditions in the neck cyst, sinus or fistula. They usually occur unilaterally and are seen in the lateral aspect of the neck in late childhood or early adulthood. If older adults come with this type of presentation, metastatic lymphadenopathy, lymphoma or tuberculosis are needed to be excluded. ${ }^{8} \quad$ No gender predilection has been reported. ${ }^{9}$

The most common branchial cleft anomalies arises from the second cleft. Around $75 \%$ of second branchial cleft abnormalities are cysts. ${ }^{10}$ Second branchial cleft fistulas and sinuses are less common. ${ }^{11,12}$

The most accepted classification of second branchial cleft anomalies was given by Bailey $\mathrm{H}$. He classified second branchial cleft cysts into four types. The type I variant is the most superficial and lies along the anterior surface of the sternocleidomastoid muscle, just deep to the platysma muscle. The type II cyst lies along the anterior surface of the sternocleidomastoid muscle, lateral to the carotid space, and posterior to the submandibular gland. It is the most common type. A type III cyst extends medially between the bifurcation of the internal and external carotid arteries upto to the lateral pharyngeal wall. The type IV cyst lies in the pharyngeal mucosal space and is lined with columnar epithelium. ${ }^{13}$

On ultrasonography, second branchial cleft cyst appears as well defined centrally anechoic mass with a thin peripheral wall. The cyst is compressible and shows acoustic enhancement. Sometimes, fine, indistinct internal echoes, representing debris, may be seen. On computed tomography, the second branchial cleft cysts are typically well circumscribed, homogeneously hypoattenuated masses surrounded by a uniformly thin wall. ${ }^{14}$ The sternocleidomastoid muscle is displaced posteriorly or posterolaterally, the vessels of the carotid space are pushed medially or posteromedially, and the submandibular gland is displaced anteriorly. ${ }^{11,15}$ In branchial sinus, a fistulogram can be done which gives the approximate idea of the length and direction of the tract. ${ }^{16}$ On histopathology, branchial cysts are filled with a turbid, yellowish fluid containing cholesterol crystals. The lining wall is stratified squamous epithelium with overlying lymphoid tissue. ${ }^{11,17}$ 
The treatment is complete surgical excision of the cyst. ${ }^{18}$ The standard surgery for a second branchial arch sinus is the stepladder approach with more than one incision in the neck that gives exposure of the sinus tract with less tissue dissection. The sinus tract encompassing the external sinus opening can then be removed. ${ }^{19}$

\section{CONCLUSION}

The branchial arches are the embryological precursors of the tissues of head and neck. The location, clinical symptoms and imaging findings aid in the diagnosis of this relatively common condition. Surgical excision is the mainstay of treatment.

\section{REFERENCES}

1. Golledge J, Ellis H. The aetiology of lateral cervical (branchial) cysts: past and present theories. J Laryngol Otol. 1994 Aug;108(8):653 -9 .

2. Larsen WJ, Schoenwolf GC, Bleyl SB, Brauer PR, Francis-West PH. Larsen's Human Embryology. Churchill Livingstone; 2009.

3. Waldhausen JHT. Branchial cleft and arch anomalies in children. Semin Pediatr Surg. 2006 May;15(2):64-9.

4. Vogl T. Hypopharynx, Larynx, Thyroid, and Parathyroid. In: Stark D., Bradley W. (Eds), Magnetic Resonance Imaging, MosbyYearbook. 2nd Edition. St. Louis; 1992. 1184$1243 \mathrm{p}$.

5. Koeller KK, Alamo L, Adair CF, Smirniotopoulos JG. From the Archives of the AFIP: Congenital cystic masses of the neck: Radiologic-pathologic correlation. Radiographics. 1999;19(1):121-146.

6. Ang AH-C, Pang KP, Tan LK-S. Complete branchial fistula: case report and review of the literature. Ann Otol Rhinol Laryngol. 2001;110 (11):1077-1079.

7. Zadvinskis D. P., Benson M. T., Som P. M.,Smoker W. R. K. Embryology And Congenital Cystic Lesions. In: Som P. M., Curtin H. D. (Eds), Head And Neck Imaging. St. Louis: Mosby; 1996. 754 p.

8. McClure MJ, McKinstry CS, Stewart R, Madden M. Late presentation of branchial cyst. Ulster Med J. 1998 Nov;67(2):129-31.

9. Faerber EN, Swartz JD. Imaging of neck masses in infants and children. Crit Rev Diagn Imaging. 1991;31(3-4):283-314.
10. Telander RL, Filston HC. Review of head and neck lesions in infancy and childhood. Surg Clin North Am. 1992 Dec;72(6):1429-47.

11. Som PM, Sacher M, Lanzieri CF, Solodnik P, Cohen BA, Reede DL, et al. Parenchymal cysts of the lower neck. Radiology. 1985 Nov;157 (2):399-406.

12. Michael AS, Mafee MF, Valvassori GE, Tan WS. Dynamic computed tomography of the head and neck: differential diagnostic value. Radiology. 1985;154(2):413-419.

13. Bailey H. Branchial cysts and other essays on surgical subjects in the facio-cervical region London. Engl Lewis. 1929;

14. Som P. Cystic lesions of the neck. Postgrad Radiol. 1987;7(21):1-236.

15. Harnsberger H. Handbook of head and neck imaging. 2nd Edition. St. Louis: Mosby;

16. Augustine AJ, Pai KR, Govindarajan R. Clinics in diagnostic imaging (66). Right complete branchial fistula. Singapore Med J. 2001 Oct;42 (10):494-5.

17.Benson MT, Dalen K, Mancuso A, Kerr HH, Cacciarelli A, Mafee MF. Congenital anomalies of the branchial apparatus: embryology and pathologic anatomy. Radiographics. 1992;12 (5):943-960.

18. Bajaj $\mathrm{Y}$, Tweedie $\mathrm{D}$, Ifeacho $\mathrm{S}$, Hewitt $\mathrm{R}$, Hartley BEJ. Surgical technique for excision of first branchial cleft anomalies: how we do it. Clin Otolaryngol. 2011;36(4):371-374.

19. Ford GR, Balakrishnan A, Evans JNG, Bailey CM. Branchial cleft and pouch anomalies. J Laryngol Otol. 1992;106(2):137-143. 